\title{
Collagenous colitis: the clinical and morphological features
}

\author{
F. Colina $\dagger$ \\ M.D. \\ J. A. Solis-Herruzo* \\ M.D. \\ M. T. MUNOZ-YAGÜE* \\ G. VAZQUEZ* \\ M.D. \\ M.D. \\ A. Perez-Barrios $\dagger$ \\ M.D. \\ Department of Medicine, *Unit of Gastroenterology and †Department of Pathology, \\ Ciudad Sanitaria ' $1^{\circ}$ de Octubre'. Universidad Complutense, Madrid, Spain
}

\begin{abstract}
Summary
A woman aged 23 years is described who had watery diarrhoea and colicky abdominal pain with normal results on sigmoidoscopy and barium enema. Rectal biopsy showed a thick layer of collagen in the lamina propria below the free epithelial surface. This lesion extended throughout the length of the descending colon. The only change revealed by electron microscopy was an increase in the thickness of the subepithelial collagen layer which is normally present in the colon. The maturation of the fibroblasts was normal. The lesion in this patient may be considered as a small change from the normal situation. This lesion is typical of 'collagenous colitis' of which only three other cases have as yet been published.
\end{abstract}

\section{Introduction}

Collagenous colitis is an anatomical entity which was described by Lindström (1976) in a patient who suffered from chronic watery diarrhoea and colicky abdominal pain. Histology revealed a deposit of collagen beneath the epithelial surface of the large intestine. Only two further cases with similar clinical and histological features have been described (Nielsen, Vetner and Harsløf, 1980; Bogomoletz et al., 1980). We report here the clinical features and the findings in the histology and fine structure in a new case.

\section{Case report}

The patient was a 23-year-old woman who, when seen for the first time in August 1980, gave a history of attacks of colicky abdominal pain, and watery

Correspondence: Dr J. A. Solis-Herruzo, Department of Medicine, Unit of Gastroenterology Ciudad Sanitaria $1^{\circ}$ de Octubre, Madrid, Spain. diarrhoea without blood, mucus or pus four to five times a day for the past year. These episodes did not occur with the ingestion of any particular type of food but were associated with emotional stress. She had lost $4 \mathrm{~kg}$ in weight in recent months, but there were no other symptoms. The only drug she took to control the diarrhoea was diphenoxylate. She gav ? no other personal history of disease but her matern通 grandmother had suffered from a similar disorde? No abnormality was detected on examination. All biochemical and haematological investigations showed normal findings. Bacteriological and parasitological tests were negative. No evidence of malabsorption was found. Barium meal and follow-through and barium enema were normal. Jejunal biopsy showed that the structure of the villi was normal and that there was no increase in the amount of collagen. Proctosigmoidoscopy, which was undertaken twice, and colonoscopy showed normal findings. Biopsies from the rectal and colonic mucosa were 3 taken at 20,30, 40 and $60 \mathrm{~cm}$ proximal to the anal sphincter.

\section{Histological findings}

The histological findings were the same in all the pieces of colonic mucosa. There was a continuous eosinophilic band beneath the epithelial surface of which was interrupted only by the necks of the crypts $N$ (Figs. 1 and 2). At high magnification it was clear $N$ that this band was composed of fibrils which were arranged in bundles parallel to the mucosal surface. The band was 15-36 $\mu \mathrm{m}$ thick (mean $23.2 \mu \mathrm{m}$ ). It stained blue with Masson's trichrome, red with Van Gieson-Werhoeff and it was birefringent under polarized light. It did not stain with Congo red; Thioflavine $\mathbf{T}$ did not induce fluorescence. 


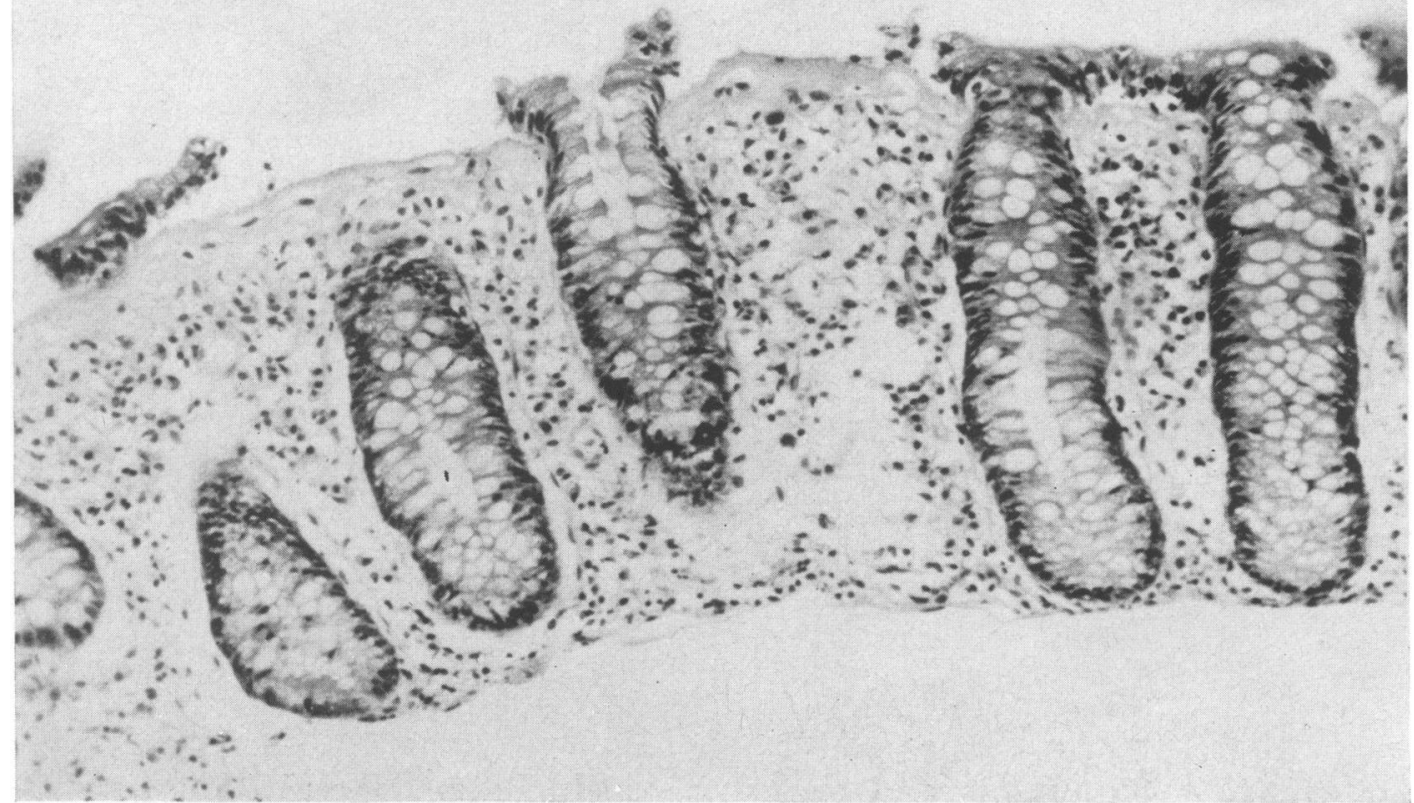

FIG. 1. Continuous band beneath the epithelial surface of the colonic mucosa, about $25 \mu \mathrm{m}$ thick. (HE, $\times 125)$.

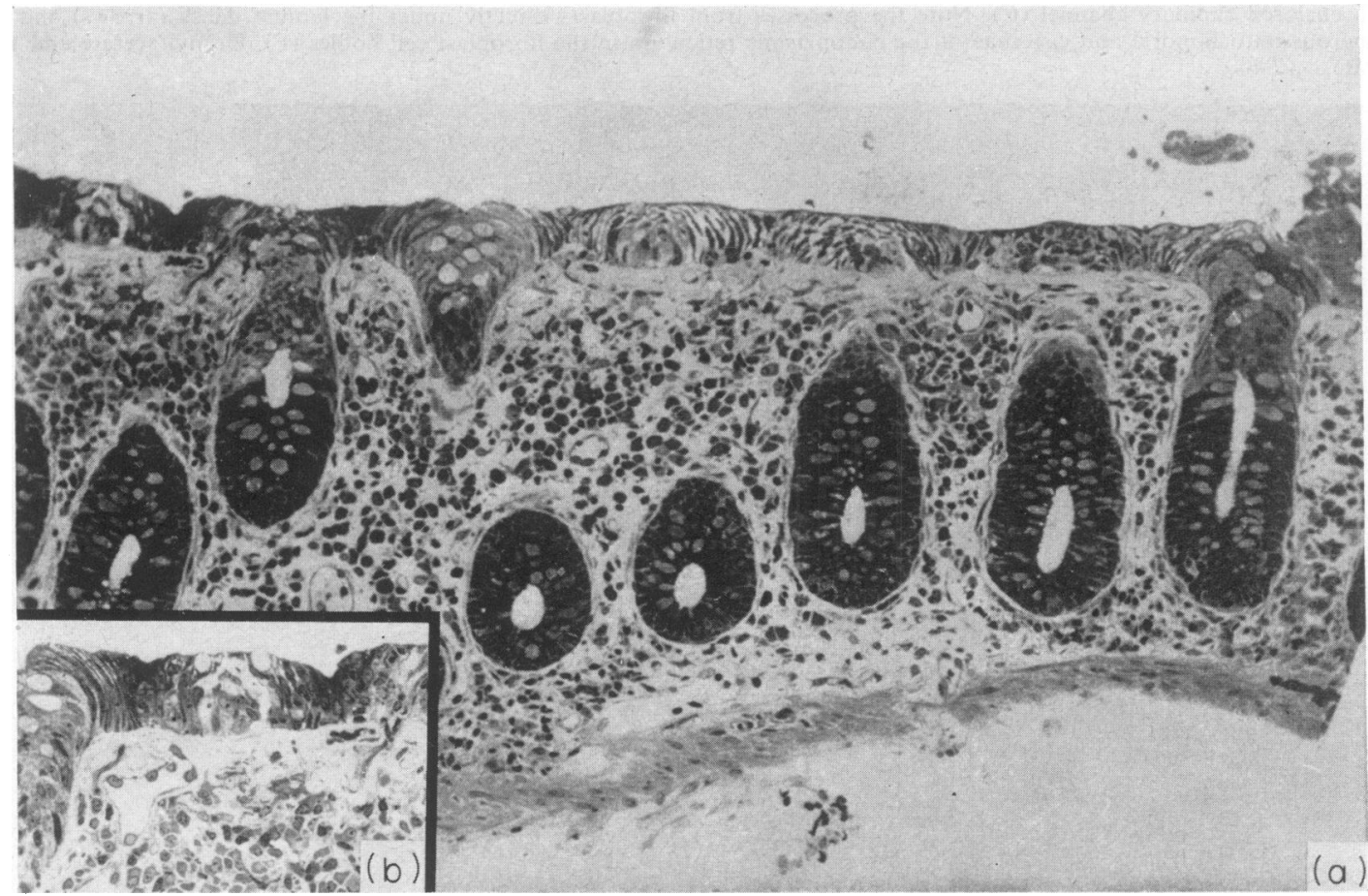

FIG. 2. (a.) The subepithelial collagen band is interrupted by the crypts. Note the difference between this band and the basement membrane of the crypt epithelium.

(b.) (Inset). High power view of the collagen band with enclosed small vascular channel. Epon sections (1 $\mu \mathrm{m})$ stained with toluidine blue; a. $\times 125 ;$ b. $\times 500$. 


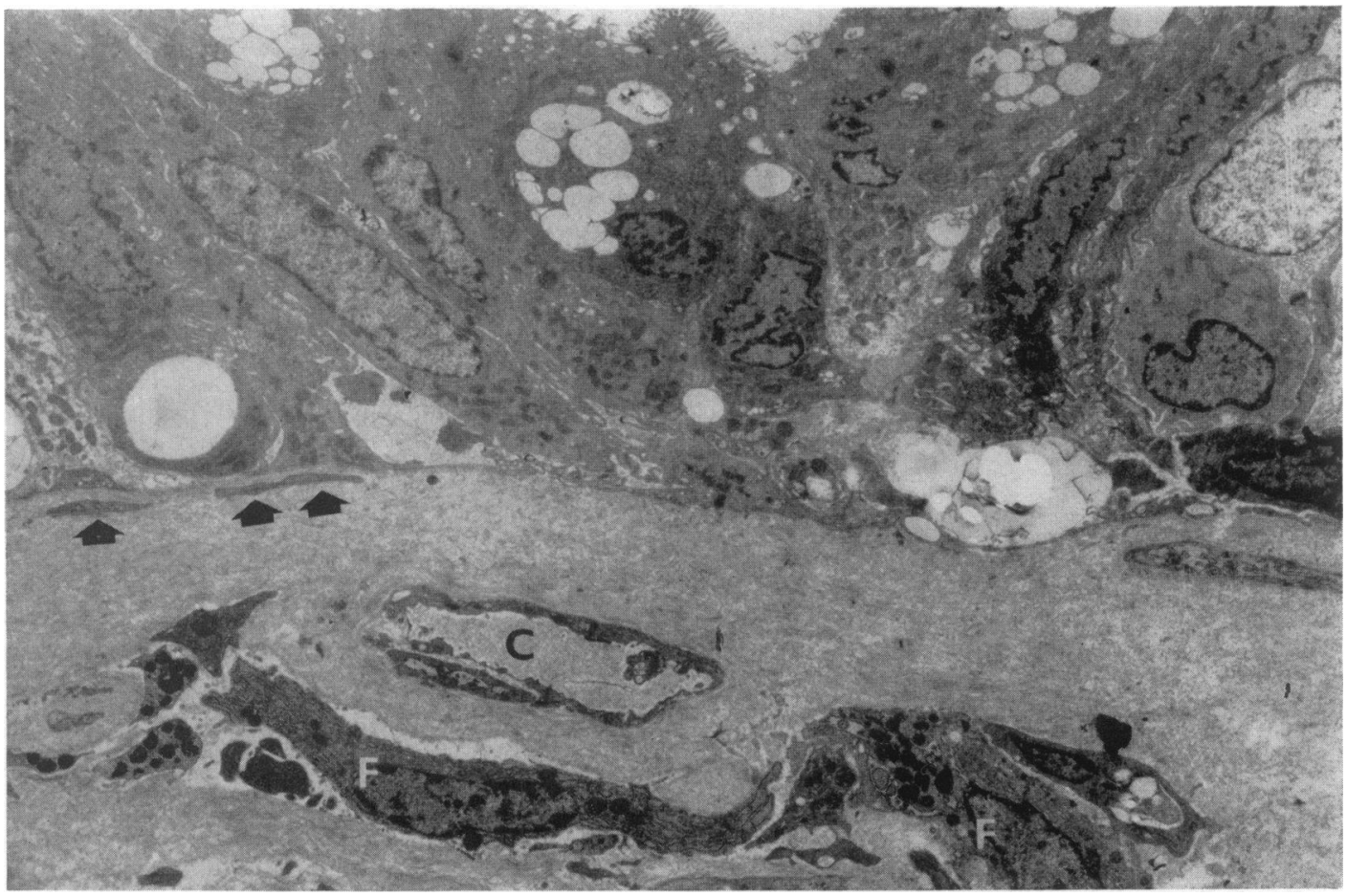

FIG. 3. Electron micrograph of the free surface between adjacent crypts. There is a thick acellular layer, under the lamina deno with enclosed capillary channel (C). Note the processes from fibroblasts directly under the lamina densa (arrows) and the numerous mitochondria and cisternae of the endoplasmic reticulum in the fibroblast cell bodies (F). Uranyl acetate and leat citrate, $\times 2400$.

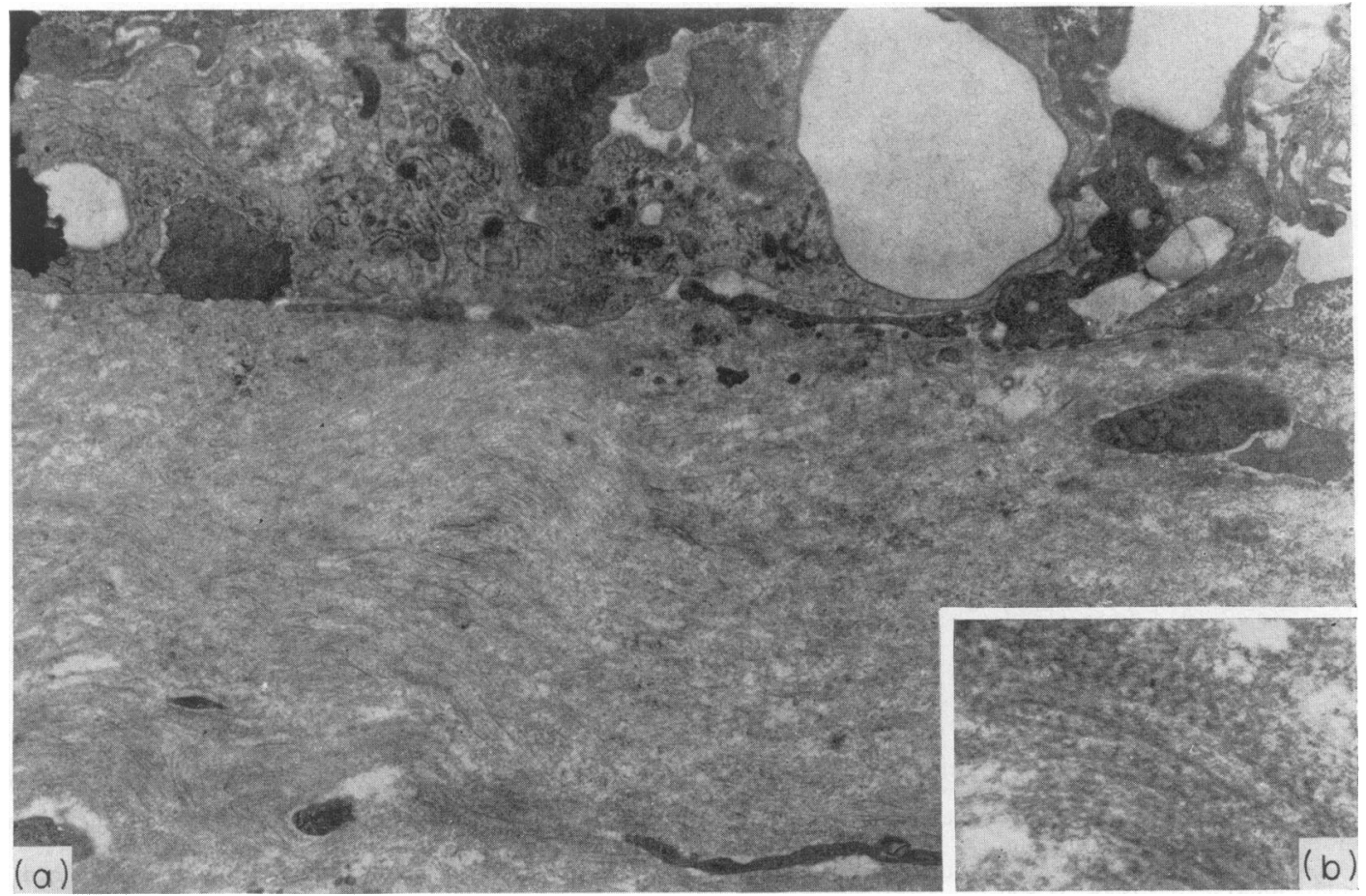

FIG. 4. (a.) Wavy layer of fibres closely grouped together.

(b.) (Inset). Typical axial periodicity of these fibres. Uranyl acetate and lead citrate; a. $\times 8000$; b. $\times 32000$. 
The architecture of the mucosal glands was normal. In the lamina propria there was slight lymphocytic infiltration with some polymorphonuclear cells, moderate oedema and capillary congestion. The morphology of the surface epithelial cells and of the glandular cells was normal (Figs. 1 and 2).

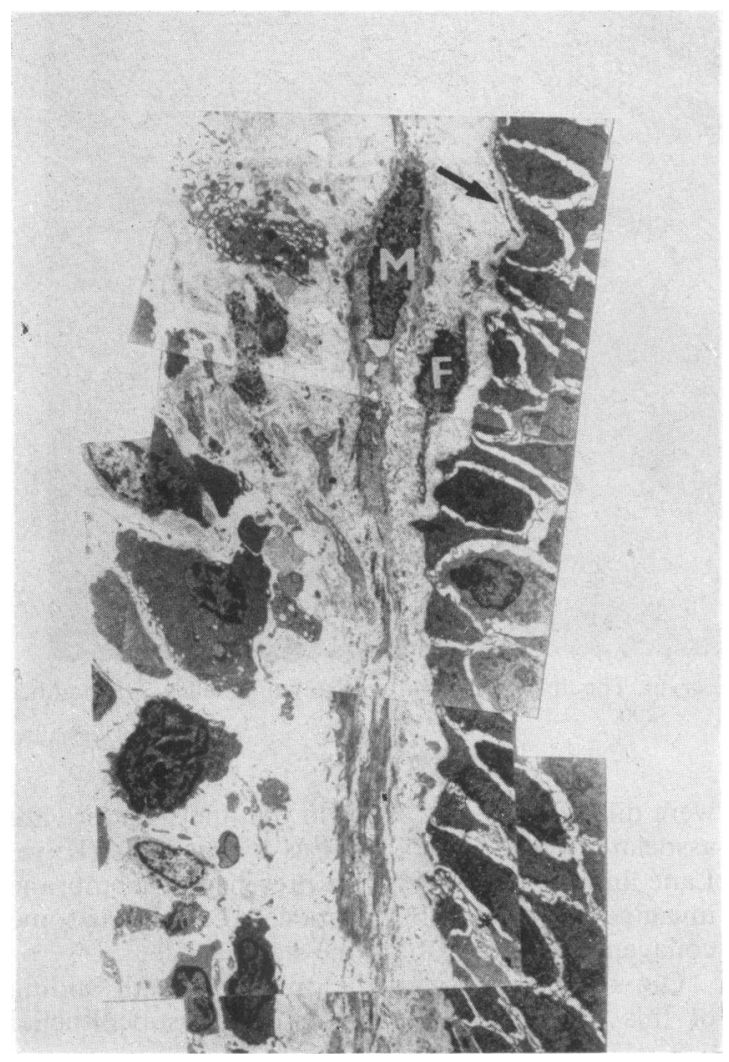

FIG. 5. Electron micrographs of the region around the crypts. The fibroblasts (F) are fusiform and their processes (arrow) lay immediately beneath the lamina densa. There are no tight bundles of fibrils. There are a smooth muscle cell (M) and lymphocytes in the lamina propria. Uranyl acetate and lead citrate, $\times 3200$.

An investigation of the ultrastructure of the colonic mucosa showed that the changes depended on which area of the crypt was examined. In the free surface between adjacent crypts, under the lamina densa, there was a thick, wavy layer of fibres arranged in a criss-cross manner and closely grouped together (Fig. 3). These fibres had transverse striations with an axial periodicity of $64 \mathrm{~nm}$ (Fig. 4). There were processes from the fibroblasts directly under the lamina densa with no fibres intervening. The fibroblasts were fusiform or star-shaped and their pro- cesses extended towards the superficial lamina densa. There were bays in the cytoplasmic membranes of the fibroblasts which were full of fibril material. The cytoplasm contained vesicles dilated by endoplasmic reticulum, well-developed Golgi apparatus, numerous mitochondria and dense lysosomes (Figs. 3 and 4). In the regions around the crypts the fibroblast cell bodies and their processes lay immediately beneath the lamina densa. There were fewer fibrils with an axial periodicity of $64 \mathrm{~nm}$ and the fibrils were arranged loosely and not grouped together in tight bundles. The fibroblasts were fusiform in shape with their long axes parallel to that of the crypt. Their cytoplasm was scanty and contained few organelles (Fig. 5). In the areas around the mouths of the crypts the changes were midway between those of the two areas described above. The cytoplasm of the fibroblasts was more granular and contained many organelles and the shape of the cells was less regular. The number of extracellular fibres increased sharply towards the surface (Fig. 6).

There were plasma cells, histiocytes, smooth muscle cells and some connestive tissue fibres in the lamina propria.

\section{Discussion}

The histological and electron microscopic changes in the patient described above are characteristic of the disease which Lindström (1976) called 'collagenous colitis'. As in the other published cases (Nielsen et al., 1980; Bogomoletz et al., 1980), the rectal biopsy showed a dense layer some $23 \mu \mathrm{m}$ thick containing very few cells under the surface epithelium of the colonic mucosa. The microscopic appearance of this layer, its staining characteristics and its fibrillary nature with striations of an axial periodicity of $64 \mathrm{~nm}$ as shown by electron microscopy are typical of collagen (Fraser and Macrae, 1973). These changes were not confined to the rectum but were also present in the biopsies taken from the descending colon. There is a similar layer of collagen under the surface epithelium in the normal colon but it is usually between 4.5 and $6.9 \mu \mathrm{m}$ thick and it is never as thick as in 'collagenous colitis' (Table 1) (Bogomoletz et al., 1980).

An examination of the fine structure in this patient showed that the only change present was an increase in the thickness of the layer of collagen under the surface epithelium. The other structures in the colonic mucosa were normal. The processes from the fibroblasts remained closely apposed to the lamina densa both around the crypts and beneath the surface epithelium. We were able to prove that there was no deposit of collagen fibres between the lamina densa and the processes of the fibroblasts (Fig. 3). The changes between the fibroblasts at the base of the crypts and those nearer the surface were 


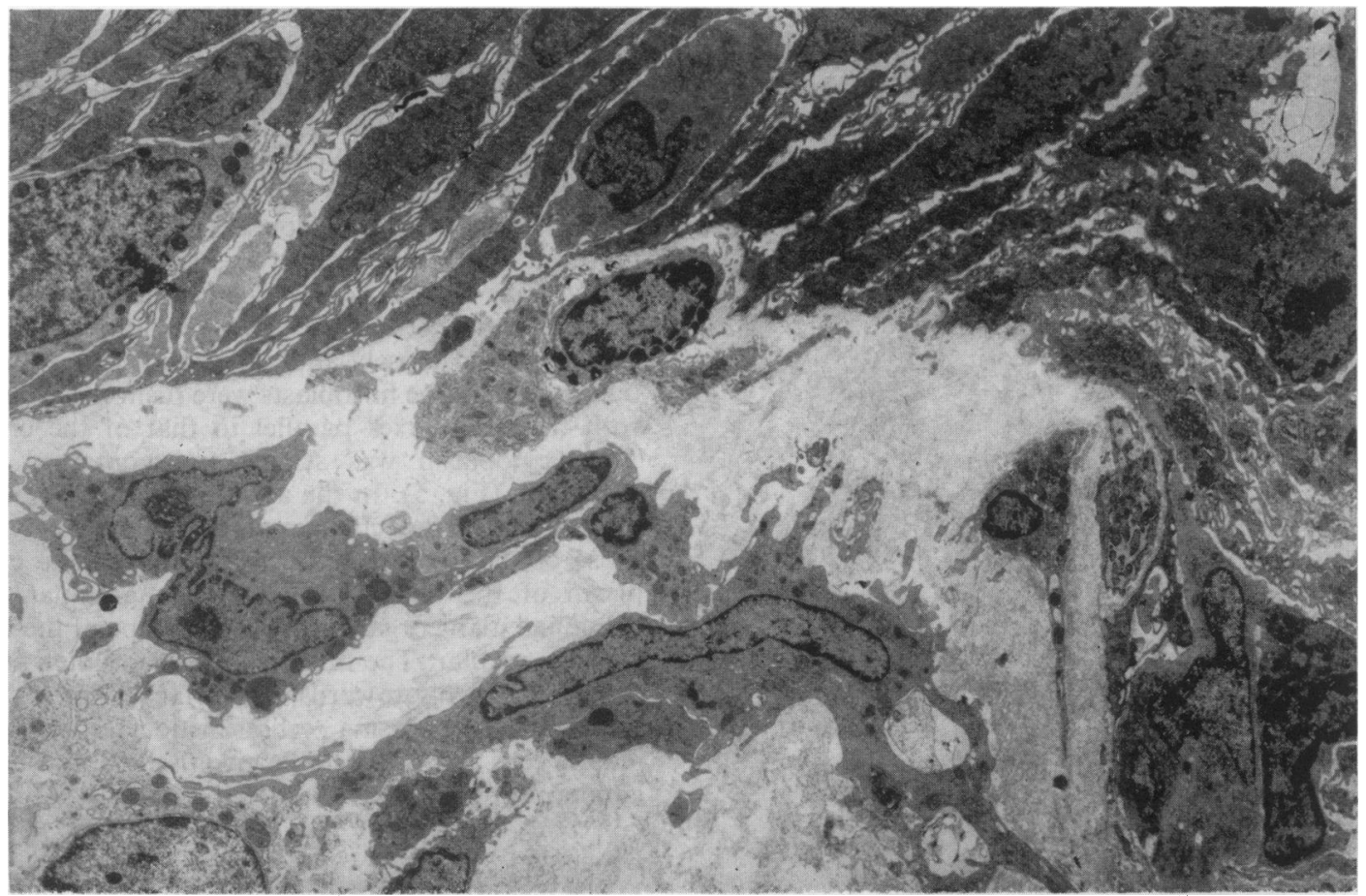

FIG. 6. Electron micrograph of the region around the mouth of the crypt. The fibroblasts contain many organelles. The numberi of fibres rise towards the surface. Uranyl acetate and lead citrate, $\times 3200$.

normal. The fibroblasts at the bases of the crypts contained few organelles and immature Golgi apparatus and these cells remained closely disposed around the crypts. The fibroblasts beneath the surface epithelium, by contrast, contained numerous mitochondria and well-developed Golgi apparatus and the cisterns in the rough endoplasmic reticulum were dilated. These changes in the fine structure are $\stackrel{\circ}{\mathbb{D}}$ associated with active synthesis by the cells (Kaye, Lane and Pascal, 1968). The presence of membrane invaginations in the fibroblastic cells containing some collagen fibres have the same significance.

Our results show that the only significant finding of this disease is an increase of the subepithelial

TABLE 1. Collagenous colitis-details of four published cases

\begin{tabular}{|c|c|c|c|c|c|c|c|}
\hline & $\begin{array}{c}\text { Age } \\
\text { (years) }\end{array}$ & Sex & Symptoms & $\begin{array}{c}\text { Stools } \\
\text { per day }\end{array}$ & $\begin{array}{l}\text { Length of } \\
\text { history } \\
\text { (years) }\end{array}$ & $\begin{array}{l}\text { Thickness } \\
\text { of collagen } \\
\text { layer }(\mu \mathrm{m})\end{array}$ & Sigmoidoscopy \\
\hline $\begin{array}{l}\text { Lindström } \\
\text { (1976) }\end{array}$ & 48 & $\mathbf{F}$ & $\begin{array}{l}\text { Watery diarrhoea } \\
\text { colicky abdominal } \\
\text { pain }\end{array}$ & $8-10$ & $2 \cdot 5$ & 一 & Normal \\
\hline $\begin{array}{l}\text { Nielsen et al. } \\
(1980)\end{array}$ & 47 & $\mathbf{F}$ & $\begin{array}{l}\text { Watery diarrhoea } \\
\text { (sometimes mucus). } \\
\text { Abdominal pain. } \\
\text { Flatulence }\end{array}$ & $3-6$ & 8 & 50 & Normal \\
\hline $\begin{array}{l}\text { Bogomoletz et al. } \\
\text { (1980) }\end{array}$ & 47 & $\mathbf{M}$ & $\begin{array}{l}\text { Watery diarrhoea. } \\
\text { Colicky abdominal } \\
\text { pain. Vomiting. }\end{array}$ & 15 & 2 & $11 \cdot 5$ & $\begin{array}{l}\text { Congested } \\
\text { and friable } \\
\text { mucosa }\end{array}$ \\
\hline $\begin{array}{l}\text { Present case } \\
\text { (1982) }\end{array}$ & 23 & $\mathbf{F}$ & $\begin{array}{l}\text { Watery diarrhoea, } \\
\text { colicky abdominal } \\
\text { pain }\end{array}$ & $4-5$ & 2 & $23 \cdot 2$ & Normal \\
\hline
\end{tabular}


collagen layer without any other remarkable changes in the cells of the region. The mechanism underlying this increase in collagen fibres is unknown. Nielsen et al. (1980) suggested that it was the result of a change in the balance of collagen formation and reabsorption. This idea is supported by the fact that the increase in collagen takes place only in the site where collagen is normally most abundant and where the fibroblasts are mature enough to produce collagen (Kaye et al., 1968; Eidelman and Lagunoff, 1972).

The symptoms have been the same in all the cases of 'collagenous colitis' published so far (Table 1). The patients complain of diarrhoea with fluid faeces which contain no blood, mucus or pus and which is accompanied by colicky abdominal pain. Proctosigmoidoscopy, colonoscopy and barium enema gave normal results in this case, as in those published by Lindström(1976) and by Nielsen et al. (1980). However, in the patient described by Bogomoletz et al. (1980) sigmoidoscopy revealed a congested and friable mucosa which bled readily and a barium enema showed slight irregularity of the mucosa of the sigmoid.

These patients' diarrhoea has been associated with the increase in thickness of the subepithelial layer of collagen. Kaye et al. (1968) thought that the collagen and polysaccharide layer had a role in the regulation of water and salt absorption. It is reasonable to suppose that, as the layer enlarges, there is increased resistance to the transport of water and a reduction in the net water and salt flow. So far there have been no investigations which show that the net flow of water and ions across the colonic mucosa is reduced in these patients.

The differential diagnosis should include amyloidosis, scleroderma, ischaemic colitis, ulcerative colitis, pseudomembranous colitis, Crohn's disease and irritable colon syndrome, but none of these shows the same histological changes. There is no apparent association between 'collagenous colitis' and 'collagenous sprue'. None of these patients suffered from malabsorption and all the biopsies of the small bowel which were taken were normal (Lindström, 1976; Nielsen et al., 1980).

\section{References}

Bogomoletz, W.V., Adnet, J.J., Birembaut, P., Feydy, P. \& DuPONT, P. (1980) Collagenous colitis: an unrecognised entity. Gut, $21,164$.

Eidelman, S. \& Lagunoff, D. (1972) The morphology of the normal human rectal biopsy. Human Pathology, 3, 389.

FraSer, R.B.D. \& MACRAE, T.P. (1973) Conformation in Fibrous Proteins pp. 344-402. Academic Press, New York.

Kaye, G.I., Lane, N. \& Pascal, R.R. (1968) Colonic pericryptal fibroblast sheath: replication, migration and cytodifferentiation of a mesenchymal cell system in adult tissue. II. Fine structural aspects of normal rabbit and human colon. Gastroenterology, 54, 852.

LiNDSTRöM, C.G. (1976) 'Collagenous colitis' with water diarrhoea-a new entity?. Pathologia Europea, 2, 87.

Nielsen, V.T., Vetner, M. \& HarsløF, E. (1980) Collagenous colitis. Histopathology, 4, 83. 